\title{
Coevolution of acoustical communication between obligate avian brood parasites and their hosts
}

\author{
Jiaojiao Wang, Qihong Li and Canchao Yang * (D)
}

\begin{abstract}
The mutually antagonistic processes producing adaptations and counter-adaptations in avian brood parasites and their hosts provide a model system for the study of coevolution; this topic has long been an area of focus in ornithology and evolutionary biology. Although there is an extensive body of literature dealing with avian brood parasitism, few empirical studies have considered the effects of the coevolutionary processes associated with brood parasitism on the acoustic characteristics of parent-offspring communication. Under the strong selection pressures associated with brood parasitism, parasitic birds may, for instance, produce deceptive songs. The host may in turn evolve the ability to recognize these sounds as deceptive. At present, the mechanisms underlying the different competitive strategies employed by hosts and parasitic birds remain unclear. Here, we reviewed previous studies that investigated acoustic traits in scenarios of brood parasitism, highlighting possible adaptive functions. Using a meta-analysis, we identified no heterogeneity among studies of begging call adaptations in parasitic nestlings. However, our results may have been affected by the small number of applicable papers available for analysis. Our meta-analysis also suggested that studies of acoustic communication and transmission in adult hosts were highly heterogenous, suggesting that research methods were inconsistent among studies. Finally, we identified knowledge gaps and proposed several lines of future research.
\end{abstract}

Keywords: Acoustic communication, Brood parasitism, Coevolution, Parasitic adaptations, Anti-parasitic adaptations

\section{Background}

Birdsongs, which contain important biological information, provide an important means of communication for birds and play a very important role in all aspects of bird life history (Catchpole and Slater 2008). Birdsong is divided into songs and calls. The main functions of songs are to attract mates and defend territories (Catchpole and Slater 2008), while calls, which are relatively widely used, are used not only to defend territories, but also for other types of communication, including announcing food availability and begging for food (Marler 2004).

*Correspondence: ccyang@hainnu.edu.cn

College of Life Sciences, Hainan Normal University, Haikou 571158, China
Avian brood parasitism is a special reproductive behavior, in which brood parasites lay eggs in the nests of other birds (hosts), thereby transferring some of the reproductive cost to the hosts (Davies 2011; Soler 2014). Successful parasitism carries a greater cost for hosts than nest predation because the parasitized hosts must invest time and effort caring for the parasitic egg; the parasitized host thus has fewer opportunities to re-nest and reproduce than when a nest predator consumes eggs or young directly (Rothstein 1990; Yang et al. 2019). Therefore, potential hosts must have appropriate defenses against nest parasitism.

The process of coevolution between obligate parasitic birds and their hosts has received considerable attention (Davies 2011). Brood parasitism, specifically the 
co-evolution of visual acuity in hosts and visual trickery in brood parasites, has been well studied (Langmore and Spottiswoode 2012). In contrast, the coevolution of auditory traits is less well investigated. Compared with visual strategies, auditory traits are more plastic and can be rapidly learned; for example, some parasitic nestlings can simulate the begging calls of host nestlings within a few days (Jamie and Kilner 2017; Rojas Ripari et al. 2018).

Due to the reciprocal selection pressures between brood parasites and their hosts, each has evolved a series of strategies designed to improve fitness. For example, hosts may use nest defense (Welbergen and Davies 2008), egg recognition (Yang et al. 2014, 2020a), and nestling recognition (Langmore et al. 2003), while parasites may use rapid spawning behaviors (Davies 2011), raptor mimicry (York and Davies 2017), egg mimicry (Attard et al. 2017; Yang et al. 2020b), and nestling mimicry (De Mársico et al. 2012).

The coevolution of auditory strategies has also been observed between brood parasites and hosts. For bird hosts, nest defense is first line of resistance to nest parasitism (Welbergen and Davies 2009; Feeney et al. 2012): when encountering parasites, the host emits alarm calls, which are transmitted not only among conspecifics but also to other species (Yu et al. 2016, 2019a). For parasitic birds, finding a host nest and successfully laying eggs poses a challenge; some female parasites mimic the songs of raptors in order to deceive the host (York and Davies 2017), and some parasites locate host nests by listening to host songs (Uyehara and Narins 1995; Clotfelter 1998; Banks and Martin 2001; Hauber et al. 2002). Once the parasitic parents successfully parasitize the nest, evading host defenses, and once the parasitic egg has successfully hatched, the parasitic nestlings must imitate communications between the host parents and offspring. In addition, the parasitic chick must use various strategies to beg the adoptive parent for extra food to outcompete the host nestlings (Davies and Brooke 1989). For example, just as parasites lay eggs mimicking host eggs, parasitic nestlings may mimic the calls of host nestlings (e.g. Madden and Davies 2006; Rojas Ripari et al. 2018) so as to avoid recognition by foster parents; parasitic nestlings may even exaggerate their calls to increase parental care (e.g. Davies et al. 1998; Lichtenstein 2001; Gloag and Kacelnik 2013). Indeed, the begging calls of parasitic nestlings are generally louder than those of corresponding host nestlings (Davies et al. 1998). Parasitic nestlings must also recognize alarm information transmitted by foster parents when danger approaches (Davies et al. 2004; Madden et al. 2005a; Haff and Magrath 2012). To combat these strategies, some chronically-parasitized hosts have evolved the ability to recognize the begging calls of some parasitic nestlings as false (McLean and Griffin
1991; Langmore et al. 2003; Colombelli-Négrel et al. 2012, 2016). It has also been suggested that host nestlings might change their begging behaviors to counteract the a priori advantages of brood parasitic nestlings (Hauber and Kilner 2007; Pagnucco et al. 2008; Boncoraglio et al. 2009).

At present, it remains unclear whether defenses and counter-defenses based on auditory communication are universal. Thus, in order to better understand host/parasite co-evolution, it is urgent to more comprehensively study the coevolution of acoustical communications between hosts and brood parasites. Further investigations of the specific information contained in the complex vocalizations of hosts and brood parasites will improve our knowledge of the evolutionary and coevolutionary processes shaping acoustic communication. In this study, we aimed to review current progress towards an understanding of the role of acoustic communications in the evolution of host defenses and parasite counterdefences. We summarize the shortcomings of previous studies of this topic, and suggest directions for future research.

\section{A brief introduction to the function of acoustical communication in birds}

The relationships among organisms are realized by the transmission of information between senders and receivers through different communication modes (Hurd and Enquist 2005; Partan 2013), including auditory, visual, olfactory, and tactile (Partan 2013; Rubi and Stephens 2016). Because acoustical communication can be used in the dark over long distances (Slabbekoorn and Smith 2002; Whittingham et al. 2004), it plays an invaluable role in bird life (Catchpole and Slater 2008). Furthermore, the potential similarities between complex birdsongs and human language are of increasing interest to researchers (Fishbein et al. 2020). To date, studies of birdsong have made important contributions in many fields, including neurobiology (Nieder and Mooney 2020) and ethology (Catchpole and Slater 2008).

Birdsong is divided into songs and calls, both of which contain important biological information (Marler 2004). Songbirds have a complex vocal system that is primarily used to occupy territories and attract mates (Catchpole and Slater 2008). However, vocal communication is also important in sub-oscines and non-passerines (Rek 2014; Wojas et al. 2018). In contrast to songs, calls are used more extensively, often in life-and-death situations; call functions include alarm responses to predators or parasitic birds (Suzuki 2012, 2014; Yu et al. 2017b; Wang and Yang 2020), declarations of food availability (Marler 2004; Madden et al. 2005a), contact maintenance (Kondo and Watanabe 2009), territorial competition (Hauber and Dearborn 2003), cries 
for help from adults or nestlings (Marler 2004), and begging for food by females or nestlings (Budden and Wright 2001; Cantarero et al. 2014). Avian brood parasites that lay eggs in host nests and transfer all reproductive costs to the hosts (Davies 2011; Soler 2014) may also protect their nesting and spawning areas, thereby protecting this important reproductive resource from other parasitic birds or conspecifics (Hauber and Dearborn 2003). Female brood parasites may mimic raptors to lure hosts away from the nest (York and Davies 2017), while parasitic nestlings may mimic host nestlings to deceive the foster parents (Langmore et al. 2008; Anderson et al. 2009; De Mársico et al. 2012; Jamie and de Silva 2014) or trick the foster parents into providing more food (Rivers 2007; Gloag and Kacelnik 2013).

Sounds are species-specific, and may also be sex- or even individual-specific. In some species, sound is the main method used to identify conspecifics, potential mates, and intraspecific individuals (Godard 1991; Villain 2016; Moskát et al. 2017). Birds not only identify relatives, mates, and offspring in noisy environments, but can also distinguish neighbors and strangers using sound. For example, Common Cuckoos (Cuculus canorus) respond more strongly to the calls of strangers than to the calls of familiar neighbors (Moskát et al. 2017). The ability to recognize neighbors and unfamiliar individuals through sound is important when defending a territory and maintaining territorial relationships. A territory owner is typically more inclined to have stable neighbors so as to avoid aggression; males with non-aggressive neighbors have more time and energy to pursue a mate (Godard 1991). Birds use sound not only for intraspecific communication (Dutour et al. 2019; Yu et al. 2019a), but also for communication with other species (Haff and Magrath 2012; Yu et al. 2019a), even mammals (Flower et al. 2014). Finally, sound can represent a "code", playing an important role in the identification of conspecific nestlings by other adults, and in the sound learning of the offspring (Colombelli-Négrel et al. 2014, 2016; Louder et al. 2019).

To improve fitness, hosts and parasites have evolved a series of anti-parasitic and parasitic strategies, respectively; the sounds made by hosts and parasites thus should also have undergone a series of changes through the coevolutionary process (Davies 2000, 2011; Langmore et al. 2003; Trnka and Prokop 2012; Yang et al. 2014; York and Davies 2017). Moreover, sound signals should play an important role, not only in adult-adult communication, but also in parent-offspring communication.

\section{Acoustical behavioral adaptations in obligate brood parasites}

Acoustic adaptations in adult parasites

Because nest defense is the first line of host resistance to parasitism (Welbergen and Davies 2009; Feeney et al. 2012), the identification of suitable host nests is the critical for brood parasites. Indeed, prior to laying parasitic eggs in the host nest, the brood parasite must accurately identify the target host and determine the host nest location. At present, the mechanisms by which parasitic birds recognize the songs of host species and locate their nests are not fully understood. Some studies of the Brown-headed Cowbird (Molothrus ater) suggested that host nests were located by parasites based on the intensity of host activity and the natural vocal frequencies of adult host calls (Uyehara and Narins 1995; Clotfelter 1998; Banks and Martin 2001), rather than based on nest defense behaviors, such as host alarm calls (Gill et al. 1997). In addition, Brown-headed Cowbirds recognized hosts' natural songs (Hauber et al. 2002), and tended to choose hosts producing less complex sounds with shorter song-burst intervals (Garamszegi and Avilés 2005). In contrast, some parasites do not depend on host singing behaviors or natural song characteristics (Avilés et al. 2009; Capek et al. 2017), but rather locate nests using host alarm calls (Marton et al. 2019).

After locating host nests, parasites must evade the host defenses in order to enter the nest and lay eggs. Cuckoo and hawk eyes are similar to those of humans (Rackham 1997). However, although some studies have shown that cuckoos can visually mimic raptors (Voipio 1953; Davies and Welbergen 2008; Welbergen and Davies 2011; Trnka and Prokop 2012; Trnka et al. 2012, 2015; Gluckman and Mundy 2013; Lyon and Gilbert 2013; Thorogood and Davies 2013; Trnka and Grim 2013; Feeney et al. 2015; Liang and Møller 2015; Møller et al. 2015), few studies have investigated whether parasites also mimic raptor sounds. Some playback experiments have shown that the rufous colors of female cuckoos are probably not intended to mimic kestrels, but rather to avoid sexual harassment by males (Lee et al. 2019). Recent studies have shown that female cuckoos may deceive their hosts via sound: the calls made by female cuckoos after laying parasitic eggs in the host nest mimic those of hawks, thereby contributing to the illusion that predators are nearby, and thus leading the hosts to shift attention from nest protection to self-protection (York and Davies 2017). Nevertheless, Deng et al. (2019) found that vocal activity in female cuckoos did not peak at laying time; Yoo et al. (2020) suggested that the signing activities of female and male cuckoos peak around dawn, not in the afternoon. In addition, previous studies have shown that female cuckoos reduced the risk of discovery by lowering their call rate (Ranger 1955; Norman and Robertson 1975; Honza et al. 2002). Kim et al. (2017) showed that structures of the sounds produced by parasitic species were relatively similar, and might thus be related to parasitic behavior. 
One aspect of nest defense against brood parasitism is the ability of the host to accurately recognize the sounds produced by the adult parasites (Additional file 1: Table S2). However, visual information may also be needed to ensure successful nest defense. Therefore, parasitic birds may also use various tricks during parasitism. Although a relatively large body of work has investigated the use of sound by parasitic birds to locate host nests, few works have investigated the mimicry of raptors by parasitic birds during parasitism (Table 1 ). Thus, the pervasiveness and universality of raptor-mimicry have yet to be validated. According to our own observations and those of Yoo et al. (2020), some parasites produce calls both day and night; however, the functions of nighttime calls are unknown. Additionally, it is unclear whether adult parasites communicate with their offspring by sound. In summary, more studies of calling in adult parasites are needed to understand in order to understand call function.

\section{Begging-call adaptations in parasitic nestlings}

One of the most striking systems for studying begging behavior is obligate avian brood parasitism; this particular reproductive behavior is found in about $1 \%$ of the world's birds (Davies 2000). Under parasitic pressure, some hosts have evolved the ability to recognize parasitic nestlings (Langmore et al. 2003; Colombelli-Négrel et al. 2012). To combat this and avoid recognition, some parasitic nestlings visually mimic host nestlings (Payne and Payne 2002; Langmore et al. 2011; De Mársico et al. 2019; Noh et al. 2018), mimic host nestling begging calls (Courtney 1967; Mundy 1973; Morton and Farabaugh 1979; Mclean and Waas 1987; Redondo and Reyna 1988;
Langmore et al. 2003, 2008; Madden and Davies 2006; Anderson et al. 2009; De Mársico et al. 2012, 2019; Jamie and de Silva 2014), or mimic host adult calls (Mundy 1973; Jamie and de Silva 2014). Parasites mimic the begging behaviors of host nestlings not only in non-evicting species (Mundy 1973; De Mársico et al. 2012), but also in some evicting species (Mclean and Waas 1987; Madden and Davies 2006; Anderson et al. 2009). To date, 47 studies have investigated the effects of sound mimicry by parasitic nestlings on host nestlings or host adults; these 47 studies include 31 species of parasites (22 species of Cuculidae, three species of Icteridae, two species of Viduidae, and four species of Indicatoridae) on six continents, with studies in Africa and Oceania together accounting for more than half of all studies (North America, 6.25\%; South America, 6.25\%; Oceania, 21.88\%; Africa, 35.94\%; Europe, 14.06\%; Asia, 15.63\%). Across these studies, $56.25 \%$ showed that the parasitic offspring mimicked the calls of the host nestlings or host adults, while $43.75 \%$ found no evidence of mimicry. However, mimicry was mostly judged subjectively (72.88\% of all studies); only $28.13 \%$ of all studies assessed begging calls quantitatively (e.g., Mundy 1973; Mclean and Waas 1987; Redondo and Reyna 1988; Madden and Davies 2006; Jamie and de Silva 2014). Moreover, some of the quantitative studies used small sample sizes or measured only a few sound parameters (e.g., Mclean and Waas 1987; Redondo and Reyna 1988; Anderson et al. 2009).

The structures of the begging calls produced by various parasitic nestlings altered when the parasitic nestlings were transferred to the nests of different host species (Madden and Davies 2006; Langmore et al. 2008) or even to the nests of non-host species (Rojas Ripari et al. 2018).

Table 1 Studies of the acoustic adaptations of parasites to date

\begin{tabular}{|c|c|c|c|c|}
\hline Parasitic adaptations & $\begin{array}{l}\text { Number of parasitic } \\
\text { species }\end{array}$ & $\begin{array}{l}\text { Proportion of total } \\
\text { parasitic species }\end{array}$ & $\begin{array}{l}\text { Number of published } \\
\text { papers }\end{array}$ & $\begin{array}{l}\text { Proportion } \\
\text { of total } \\
\text { literature* (\%) }\end{array}$ \\
\hline \multicolumn{5}{|l|}{ Parasitic adults } \\
\hline Locate host nest by sound & 2 & $2.00 \%$ & 9 & 6.62 \\
\hline Mimic raptor sound & 1 & $1.00 \%$ & 1 & 0.74 \\
\hline Shorten own call rate & 6 & $6.00 \%$ & 5 & 3.68 \\
\hline Other adaptations & - & - & 1 & 0.74 \\
\hline Total & 5 & $5.00 \%$ & 16 & 11.76 \\
\hline \multicolumn{5}{|l|}{ Parasitic nestlings } \\
\hline Mimic host begging calls & 31 & $31.00 \%$ & 47 & 34.56 \\
\hline Supernormal stimuli of begging & 6 & $6.00 \%$ & 15 & 11.03 \\
\hline Identify host alarm calls & 2 & $2.00 \%$ & 3 & 2.21 \\
\hline Other adaptations & 3 & $3.00 \%$ & 3 & 2.21 \\
\hline Total & 31 & $31.00 \%$ & 68 & 50.00 \\
\hline
\end{tabular}

* Total literature refers to all published literature on the coevolution of acoustic communication 
These results provide evidence that effective begging displays are developed based on acquired experience, and suggest that the begging calls of parasitic nestlings are plastic. However, other studies have reported contradictory results (Butchart et al. 2003; Soler 2017; Samaš et al. 2020). Thus, it remains controversial whether various races of parasitic nestlings alter their begging calls to match those of their hosts. This incongruence among study results requires further exploration; it may be that parasitic chick calls have other, as yet undetermined, functions.

Parasitic nestlings may use various begging strategies to induce the host parent to feed the parasite more frequently than the host nestlings (Additional file 1: Table S1) (Lorenzana and Sealy 1996). In addition to the vocal mimicry of host begging calls, some parasitic nestlings may exaggerate begging signals to compete with distant host nestlings or with large numbers of nestmates, leading to preferential feeding (i.e., the signal exaggeration hypothesis) (Dawkins and Krebs 1979; Caro et al. 2016). Nestlings of the Shiny Cowbird (Molothrus bonariensis), for example, call for food at a much faster rate than those of the host (House Wren, Troglodytes aedon); the frequency of food calls remained high even when the nestlings were transferred to the nests of non-host species (Gloag and Kacelnik 2013). Davies et al. (1998) found that the begging intensity of a single one-week-old cuckoo nestling was similar to the combined begging frequencies of four Reed Warbler (Acrocephalus scirpaceus) nestlings. Parasitic nestlings may use a combination of audio and visual elements to stimulate host parents. For example, Kilner et al. (1999) showed that, in Reed Warbler nests, the frequent begging calls produced by cuckoo nestlings enabled the cuckoo nestlings to compete effectively with the Reed Warbler host nestlings, despite the cuckoos' smaller gape area (i.e., the integration of signals hypothesis).

However, there are also cases where parasitic nestlings do not produce more extravagant calls than host nestlings (Soler 2002; Rivers et al. 2013). Moreover, it has been shown that non-evicting parasitic nestlings that do not mimic host begging calls still receive parental care, without the help of their host nestmates (Rojas Ripari et al. 2019); in such cases, the begging strategies employed by the parasitic nestlings are unknown. Parasitic nestlings of different genders may also employ different begging behaviors (Hauber and Ramsey 2003; but see Abraham et al. 2015).

Nest predation is one of the main factors that affects nestling begging behaviors. Previous studies have found that experimental nests with noise are more likely to be destroyed than quiet nests (Haskell 1994, 1999; Leech and Leonard 1997; Dearborn 1999). Parasitic nestlings are generally louder than their host nestlings when begging for food (Davies et al. 1998), and thus, their calls may be limited by predation. However, a recent study indicated that the natural begging calls of cuckoos have no predation cost (Jelínek et al. 2019).

In summary, many studies have addressed the mimicry of host begging calls by the nestlings of parasitic birds; the studied species account for $31 \%$ of the all known parasitic bird species, and these studies represent $34.56 \%$ of all of the relevant studies published to date (Table 1). However, information about begging calls is lacking for $69 \%$ of all parasitic birds, indicating that further research is necessary. Here, we used a meta-analysis to determine whether the studies of parasitic nestling strategies were consistent. To perform this analysis, we first manually filtered the complete matched data from all relevant studies (Additional file 1: Table S1). Then, we used the meta package (version 4.13-0) in R studio (version 3.6.3) to perform a meta-analysis based on the characteristics of the data. Ideally, an analysis of the heterogeneity of the results of the published studies would have included the number of events and the experimental observations for each experiment. Although raw data containing effect sizes were not reported in most of the previously published studies, we acquired matched sample sizes for experimental and control groups manually. Our results showed that the sizes of the research projects did not differ significantly, and that $I^{2}$ was not heterogeneous $\left(I^{2}=0 \%\right.$, $\tau^{2}=0, p=0.35$, where $I^{2}$ and $p$ stand for quantitative tests for heterogeneity, and $\tau^{2}$ is the difference among studies, which reflects the degree of inter-study heterogeneity). However, our results may have been affected by the limited number of published papers; only 15 appropriate papers were located, and only five could be included in the meta-analysis. This indicated that studies on the differentiation and specialization of begging calls in parasitic nestlings are scarce. Additional empirical studies are needed to determine whether begging call adaptations in parasitic nestlings are specialized to different host species, or to different host races within the same host species. It is possible that some parasitic nestlings do alter the structures of their begging calls among hosts, and that, instead, certain begging characteristics stimulate the preferential feeding of parasitic nestlings in multiple hosts. We suggest that, in general, acoustical analyses and playback experiments should be combined to more comprehensively explore this possibility.

\section{Adaptation to host alarm calls in parasitic nestlings}

In general, the more frequently and intensively a nestling begs for food, the more food the parents will provide (Kacelnik et al. 1995; Budden and Wright 2001). However, in order to ensure begging-call authenticity and 
to prevent an endless increase in begging, begging calls entail two types of cost: increased energy consumption (Chappell and Bachman 2002) and increased predation risk (Haskell 2002; Haff and Magrath 2011). As studies indicate that begging consumes little energy (Leonard et al. 2003), nest predation may be the main selective factor affecting begging rate and intensity (Jelínek et al. 2016).

The expensive nature of begging has led to behavioral adaptations in both parents and offspring: nestling begging behaviors may be regulated both by "on" signals (such as food calls) and "off" signals (such as antipredator alarms) (Madden et al. 2005a). Begging calls are unlikely to increase nestling risk when the parents come to the nest. Indeed, in response to alarm calls from parents or other birds, chicks will crouch down or become silent (Madden et al. 2005a; Haff and Magrath 2012). For example, nestlings of the White-browed Scrub Wren (Sericornis frontalis) eavesdrop on heterospecific alarm calls and respond by suppressing begging so as to reduce the risk of predation (Haff and Magrath 2012). In addition to warning the nestlings to stop begging (Davies et al. 2004; Madden et al. 2005a), parental alarm calls can encode information about the type of predator and the degree of urgency, thereby enabling their nestlings to respond in the most appropriate way (Platzen and Magrath 2005). In the Great Tit (Parus major), for example, parental alarm calls elicit a predator-specific response in nestlings: nestlings leave the nest when they hear snake-specific adult alarm calls, but crouch down when they hear corvid-specific adult alarm calls (Suzuki 2011). However, a study of Eastern Phoebes (Sayornis phoebe) showed that nestlings did not respond to parental alarm calls (Madden et al. 2005a). Finally, some studies have shown that nestlings respond to predator calls by suppressing begging (Yasukawa et al. 2020).

Most previous studies have focused on the responses of altricial nestlings to the alarm calls produced by adults in response to predators. However, in parasitized host nests, the parasitic nestlings make louder and stronger sounds (e.g., during begging) than do the host nestlings (Soler 2017). In addition, parasitic nestlings are sometimes much larger than host nestlings. Thus the parasitic nestlings should more easily attract predator attention both visually and aurally. However, Soler et al. (2019) showed that Great Spotted Cuckoo (Clamator glandarius) nestlings had a lower misjudgment rate than host nestlings with respect to begging behavior. That is, parasitic nestlings may be better able to receive danger messages from their foster parents than host nestlings. However, only a few studies have investigated the response of parasitic nestlings to the alarm calls of foster parents. In addition, all of the bird species reviewed in these studies occur in
Europe and North America. For example, Davies et al. (2006) found that cuckoo nestlings reduced begging in response to the alarm calls of Reed Warblers, but after these nestlings were transferred to the nests of an alternative host, Robins (Erithacus rubecula) or Dunnocks (Prunella modularis), they did not respond to the alarm calls of the new foster parents. Moreover, cuckoo nestlings in the nests of Redstarts (Phoenicurus phoenicurus), another typical cuckoo host, did not respond to the alarm calls of Reed Warblers or Redstarts (Davies et al. 2006). However, another study of Common Cuckoo nestlings in Redstart nests found that the cuckoo nestlings responded to host alarm calls by freezing and reducing begging (Khayutin 1985). Madden et al. (2005b) found Brown-headed Cowbirds also suppressed begging in response to the alarm calls of Red-winged Blackbirds. Thus, it appears that parasitic nestlings of the same species in different regions may have different responses to host alarm calls. However, as this hypothesis is based on only a few studies, further verification is needed. It also remains unclear whether nestlings parasitizing different host races exhibit specialized responses, and whether parasitic nestlings eavesdrop on the alarm calls of sympatric non-host birds.

Finally, some parasitic birds are nest predators of hosts (Soler et al. 1995), and hosts give specific alarm calls when facing parasitic birds (Soler et al. 1995; Welbergen and Davies 2008; Yu et al. 2017a, 2019a). It remains to be verified whether parasitic nestlings ignore alarm calls concerning parasite risk by host parents, or instead regard such calls as indicating danger.

Thus, our review of the relevant material indicates that empirical studies are needed to investigate whether nestlings that parasitize a variety of host species and races have host-specific responses to host alarm calls. For host populations under high predation pressure, future studies must investigate whether parasitic nestlings experience a tradeoff between begging and predation, and must clarify whether parasitic nestlings adjust begging calls or characteristics according to predation pressure.

\section{Acoustical anti-parasitic adaptations in hosts} Acoustic communication and transmission in adult hosts Nest defense is the frontline response of hosts to nest parasitism (Feeney et al. 2012). Successful nest defense can effectively reduce brood parasitism (Welbergen and Davies 2009). To successfully defend the nest and maximize fitness, the host must first obtain information about the parasite (Yu et al. 2019a, b). Generally, hosts obtain relevant threat information in two ways: as individuals (i.e., through direct interaction with the environment) and socially (i.e., where threat information or cues are provided by other individuals Dall et al. 2005;). Some 
hosts not only distinguish cuckoos from other threatening or non-threatening species (Welbergen and Davies 2008; Trnka and Prokop 2012; Yang et al. 2014; Li et al. 2015; Ma et al. 2018; Yu et al. 2019a; Wang and Yang 2020), but may also adjust the strength of nest defense according to the type of enemy and the degree of parasitism risk (Montgomerie and Weatherhead 1988; Caro 2005; Welbergen and Davies 2009; Campobello and Sealy 2010, 2018). For example, Reed Warblers attack cuckoos, but not Sparrow Hawks (Accipiter nisus) (Duckworth 1991). Furthermore, many bird species produce specific alarm calls in response to different threats. Conspecific or interspecific alarm calls convey the type, size, speed, and behavior of an intruder, allowing the receiver to respond quickly (Suzuki 2012, 2014; Book and Freeberg 2015; Yu et al. 2016, 2017a, b, 2019a; b; Cunningham and Magrath 2017; Dawson Pell et al. 2018; Kalb et al. 2019; Kalb and Randler 2019; Walton and Kershenbaum 2019; Wang et al. 2020; Wang and Yang 2020). Bird alarm calls can also be used to attract both conspecific and heterospecific neighbors; this has been referred to as the "calling for help" hypothesis (Hurd 1996). Neighbors who are attracted by an alarm call may benefit by receiving information about the presence of dangerous enemies or nearby predators (Grim 2008). Sound playback is ubiquitous in studies of vocal communication among birds, and has also been widely used in studies of fish, mammals, and insects (Rosenthal 2019). As some birds react differently to visual and vocal intruder displays (Liang and Møller 2015; Yu et al. 2017b; Adams et al. 2020), playback experiments are necessary for result verification.

Parent birds should optimize their nest defense strategy based on the tradeoff between their own survival and the loss of the nest contents (Montgomerie and Weatherhead 1988). Previous studies have shown that the host response to nest intruders varies according to breeding stage (Barash 1975; Patterson and James 1980; Duckworth 1991; Moskát 2005; Trnka and Prokop 2012; Wang and Yang 2020). For example, Duckworth (1991) showed that Reed Warbler hosts had a strong, aggressive response to Common Cuckoos during the egg stage, but largely ignored Common Cuckoos once the nestlings had fledged; the Reed Warbler responses to Jays (Garrulus glandarius) and Sparrow Hawks remained strong, regardless of the breeding stage. This behavior illustrates the effects of the reproductive value of offspring. The offspring value hypothesis predicts that nest defense level will be the highest during the nestling stage, as this adaptive response increases the value of the future generation (Smith 1977). Although most of the relevant studies have focused on the visual aspects of nest defense, the verification of host alarm sound recognition using sound playback may more fully explain host anti-parasitism strategies during the nest defense phase. We have summarized the studies of the anti-parasite nest defense strategies adopted by hosts in Additional file 1: Table S2.

We used a meta-analysis to assess the consistency of the results across the studies reviewed in this section. The meta-analysis indicated that heterogeneity among these studies was high $\left(I^{2}=61 \%, \tau^{2}=0.0614, p=0.02\right)$. Again, however, this result may be unreliable because only seven research studies could ultimately be included in analysis. This result implied that the methods used in previous studies were inconsistent. Most previous authors only recorded the responses of hosts to taxidermic mounts, and did not analyze the acoustic spectra of the alarm calls (Additional file 1: Table S2). Moreover, few studies have used alarm call playbacks to explore the communication of risk information within or among host species. The recognition of alarm calls among sympatric host species requires further study. That is, in order to understand the mechanisms underlying alarm call recognition, it is necessary to determine whether information is shared among sympatric conspecific and heterospecific birds. Although birds have been shown to respond to heterospecific alarm calls that are unfamiliar but similar to known calls with respect to acoustic structure (Fallow et al. 2013), but it is unclear whether sympatric conspecific and heterospecific species share alarm calls conveying parasite risk.

\section{Acoustic recognition of parasitic nestlings by adult hosts}

Studies of brood parasite systems have indicated that some hosts have evolved the ability to recognize parasitic nestlings (Langmore et al. 2003). There are several hypotheses concerning host recognition mechanisms: the parental-fatigue hypothesis (Grim 2006), the timelimit hypothesis (Grim et al. 2003), and the single-chick hypothesis (Anderson and Hauber 2007; Langmore et al. 2009). It may be that hosts use special acoustical "codes" to communicate with embryos during incubation, so that host parents can distinguish parasitic chicks when they make begging calls; this is known as the beggingcall mimicry hypothesis (Colombelli-Négrel et al. 2012, 2016). Furthermore, females may communicate their voice codes to their male partners, so that the males can recognize the sounds associated with parasitic nestlings (Colombelli-Négrel et al. 2012).

Although birds are known to exhibit prenatal voice learning, we were unable to find many studies of this phenomenon (Kisilevsky et al. 2009; Moon et al. 2013; Colombelli-Négrel et al. 2014, 2016; Kleindorfer et al. 2014, 2018; Dowling et al. 2016; Katsis et al. 2018; Rivera et al. 2018; Noguera and Velando 2019). In avian brood parasitism, the recognition of parasitic nestlings via prenatal voice learning has been reported in Superb 
Fairy-wrens and Red-backed Wrens (Malurus melanocephalus) (McLean and Griffin 1991; Colombelli-Négrel et al. 2012, 2016). In addition, McLean and Griffin (1991) showed that adult Grey Warblers (Gerygone igata) can distinguish the begging calls of their own nestlings from those of parasitic cuckoo nestlings. However, it remains unclear whether this type of antiparasitic adaptation is ubiquitous or unique to this particular bird group.

\section{Anti-parasitic adaptations of begging calls in host nestlings}

Parasitic nestlings generally exaggerate their calls in order to increase parental care (e.g. Davies et al. 1998; Lichtenstein 2001; Gloag and Kacelnik 2013). For example, the begging intensity of one evicting-type parasitic nestling was equivalent to that of four Reed Warbler nestlings (Davies et al. 1998). In addition, the exaggerated begging behaviors of non-evicting parasitic nestlings may help these nestlings to outcompete their nestmates, leaving to the starvation of the host nestlings (Redondo 1993). Interestingly, in order to increase feeding opportunities, host nestlings may then begin to mimic the exaggerated begging calls of the parasitic nestlings (Hauber and Kilner 2007; Pagnucco et al. 2008).

Previous studies have shown that when nestlings compete with larger or more competitive conspecific nestmates, they generally change the amplitudes and structures of their begging calls (Smith and Montgomerie 1991; Briskie et al. 1994; Price et al. 1996; Leonard and Horn 2001; Rodríguez-Gironés et al. 2002; Neuenschwander et al. 2003). As parasitic birds are distantly related to their hosts, it is natural for host nestlings to change their begging call structures to avoid parental monopolization by parasitic nestmates (Pagnucco et al. 2008). Leonard and Horn (2005) showed that, when ambient noise increases, the frequencies and amplitudes of the begging calls of Tree Swallows (Tachycineta bicolor) increase, and that parents are more likely to feed nestlings whose calls are louder than the surrounding environment; in addition, when host nestlings are fed together with noisy parasitic nestlings, the host nestlings may change the structures of their begging calls to attract parental attention. Hauber and Kilner (2007) proposed that the begging call matching between parasitic birds in the genus Vidua and their hosts may be caused by the imitation of parasite chicks by host young. Compared with host nestlings in unparasitized nests, begging frequency and volume are greater when Song Sparrow nestlings are raised with Brown-headed Cowbirds (Pagnucco et al. 2008). A study of 31 North American hosts found that the begging intensity of host nestlings increased with the probability of parasitization, indicating that the parasitic birds affected the begging behavior of host offspring
(Boncoraglio et al. 2009). However, Rivers et al. (2010a) argued that the evidence for this conclusion was insufficient, and suggested that the extent to which cowbirds affect the begging behavior of the hosts depended on the size of the host (Rivers et al. 2010b). In addition, some studies have shown that the predation rate for parasitized nests is higher than that for non-parasitized nests (Dearborn 1999).

In summary, the responses of host nestlings to brood parasitism have received less attention than the behaviors of parasitic nestlings, and few studies have explored the acoustic anti-parasitic adaptations of host nestlings (Table 2). This may be because host nestlings may not interact with parasitic nestlings due to the danger of being evicted after parasitism, or host nestlings may fail to survive because they are outcompeted when they are raised along with non-evicting parasitic nestlings. When host nestlings are reared together with parasite nestmates, host nestlings must adjust their own begging behaviors in order to compete with the parasitic nestlings and obtain sufficient food. However, few research studies have addressed this aspect of parasitism, and this topic remains controversial (Rivers et al. 2010a, b). When investigating acoustical behaviors, the relative sizes of the parasitic and host nestlings should be considered. It remains unclear whether nestlings of parasitized hosts have coevolved to produce stronger begging calls, and whether this adaptation changes with the degree of parasitism and predation pressure. Indeed, further studies should investigate how the begging calls of host nestlings are altered in response to dual pressures of parasitism and predation.

\section{Conclusions}

The coevolution between parasitic birds and their hosts continues to be a hotspot of research interest. Although the coevolution of visual signals has been well studied, the coevolution of auditory traits between hosts and parasites has been largely neglected. Here, we reviewed studies of the coevolution of acoustical communication between obligate avian brood parasites and their hosts. We conclude that both the acoustical adaptations of parasitic birds and the acoustical anti-parasitic adaptations of host birds require further research attention.

First, with respect to the acoustical adaptations of parasitic birds, it is unclear whether the songs of adult parasitic birds are used to simulate the sounds of raptors or whether these sounds have other functions. In addition, the begging calls of more than half of all parasitic nestlings remain unknown and undescribed, and it remains unclear whether these begging calls are specialized or differentiated among hosts. In future, the mimicry of host begging calls by parasitic nestlings should be analyzed 
Table 2 Studies of acoustic anti-parasitic adaptations in hosts to date

\begin{tabular}{lcc}
\hline Anti-parasitic adaptations & Number of published papers & $\begin{array}{c}\text { Proportion } \\
\text { of the total } \\
\text { literature* (\%) }\end{array}$ \\
\hline Host adults & & 6.62 \\
Identify host alarm calls & 9 & 2.94 \\
Recognize sound of parasitic adults & 4 & 1.47 \\
Social learning & 2 & 5.88 \\
Recognize parasitic adults & 8 & 2.21 \\
Adjust behavior according to parasitism risk & 3 & 2.94 \\
Make specific alarm calls & 4 & 0.74 \\
Increase incubation call rate & 1 & 1.47 \\
Alarm; protect nest & 2 & 8.82 \\
Aggressive behavior including alarm calls & 12 & 2.21 \\
Recognize sound of parasitic nestlings & 3 & 35.29 \\
Total & 48 & 2.94 \\
Host nestlings & & 2.94 \\
Adjust oneself to beg & 4 & 4 \\
Total & 4 & \\
\hline
\end{tabular}

* Total literature refers to all published literature on the coevolution of acoustic communication

quantitatively, not merely subjectively. Finally, the effects of predation pressure on parasitic nestling behavior remain to be comprehensively explored; that is, do parasitic nestlings under predation pressure quickly respond to the alarm calls of their foster parents or change their begging characteristics when facing danger?

Second, with respect to the acoustical anti-parasitic adaptations of host birds, future studies must combine sound playback experiments and acoustic spectral analyses to investigate acoustical information exchange among conspecific and heterospecific hosts. In addition, the universality of host adult birds using sound to recognize parasitic nestlings should be verified. Finally, studies should explore not only the begging behaviors of parasitic nestlings, but also how the begging behaviors of host nestlings change in response to parasitism, which is easily ignored. In particular, it is important to assess how the begging calls of host nestlings are regulated by the dual pressures of parasitism and predation. Future studies, thoroughly addressing these deficiencies, will greatly improve our understanding of the evolution and coevolution of sound signals in both host and parasitic birds in brood parasitism system.

\section{Supplementary information}

Supplementary information accompanies this paper at https://doi. org/10.1186/s40657-020-00229-2.

Additional file 1: Table S1. Studies of the begging strategies of parasitic nestlings. Table S2. Studies of nest defenses used by hosts against parasites.

\section{Acknowledgments}

We thank the anonymous reviewers for helpful suggestions that improved our manuscript.

\section{Authors' contributions}

$\mathrm{CY}$ designed the manuscript outline. JW drafted the manuscript, QL analyzed the data, and CY edited the manuscript. All authors read and approved the final manuscript.

\section{Funding}

This work was supported by the National Natural Science Foundation of China (Grant No. 31672303 to CY).

\section{Availability of data and material}

Not applicable.

Ethics approval and consent to participate Not applicable.

\section{Consent for publication \\ Not applicable.}

\section{Competing interests}

The authors declare that they have no competing interests.

Received: 2 June 2020 Accepted: 23 October 2020

Published online: 03 November 2020

\section{References}

Abraham MM, Požgayová M, Procházka P, Piálková R, Honza M. Is there a sexspecific difference between parasitic chicks in begging behaviour? J Ethol. 2015;33:151-8.

Adams DB, Kitchen DM, Bshary R. Model vs. playback experiments: the impact of sensory mode on predator-specific escape responses in saki monkeys. Ethology. 2020;126:1-13.

Anderson MG, Hauber ME. A recognition-free mechanism for reliable rejection of brood parasites. Trends Ecol Evol. 2007;22:283-6. 
Anderson MG, Ross HA, Brunton DH, Hauber ME. Begging call matching between a specialist brood parasite and its host: a comparative approach to detect coevolution. Biol J Linn Soc. 2009;98:208-16.

Attard MRG, Medina I, Langmore NE, Sherratt E. Egg shape mimicry in parasitic cuckoos. J Evol Biol. 2017;30:2079-84.

Avilés JM, Moskát C, Bán M, Hargitai R, Parejo D. Common cuckoos (Cuculus canorus) do not rely on indicators of parental abilities when searching for host nests: the importance of host defenses. Auk. 2009;126:431-8.

Banks AJ, Martin TE. Host activity and the risk of nest parasitism by brownheaded cowbirds. Behav Ecol. 2001;12:31-40.

Barash DP. Evolutionary aspects of parental behavior: distraction behavior of the Alpine Accentor. Wilson Bull. 1975;87:367-73.

Boncoraglio G, Saino N, Garamszegi LZ. Begging and cowbirds: brood parasites make hosts scream louder. Behav Ecol. 2009;20:215-21.

Book DL, Freeberg TM. Titmouse calling and foraging are affected by head and body orientation of cat predator models and possible experience with real cats. Anim Cogn. 2015;18:1155-64.

Briskie JV, Naugler CT, Leech SM. Begging intensity of nestling birds varies with sibling relatedness. Proc R Soc Lond B Biol Sci. 1994;258:73-8.

Budden $A E$, Wright J. Falling on deaf ears: the adaptive significance of begging in the absence of a parent. Behav Ecol Sociobiol. 2001;49:474-81.

Butchart SHM, Kilner RM, Fuisz T, Davies NB. Differences in the nestling begging calls of hosts and host-races of the common cuckoo, Cuculus canorus. Anim Behav. 2003;65:345-54.

Campobello D, Sealy SG. Enemy recognition of Reed Warblers (Acrocephalus scirpaceus): threats and reproductive value act independently in nest defence modulation. Ethology. 2010;116:498-508.

Campobello D, Sealy SG. Evolutionary significance of antiparasite, antipredator and learning phenotypes of avian nest defence. Sci Rep. 2018;8:10569.

Cantarero A, López-Arrabé J, Palma A, Redondo AJ, Moreno J. Males respond to female begging signals of need: a handicapping experiment in the pied flycatcher, Ficedula hypoleuca. Anim Behav. 2014;94:167-73.

Capek M, Petrusková T, Šebelíková Z, Campos Serrano J, Procházka P, Honza M, et al. Great Reed Warbler singing behavior and conspicuous song structures are not nest-location cues for the Common Cuckoo. J Ornithol. 2017;158:925-33.

Caro TM. Antipredator defenses in birds and mammals. Chicago: University of Chicago Press; 2005

Caro SM, West SA, Griffin AS. Sibling conflict and dishonest signaling in birds. Proc Nat Acad Sci. 2016;113:13803-8.

Catchpole CK, Slater PJB. Bird song: biological themes and variations. 2nd ed. Cambridge: Cambridge University Press; 2008.

Chappell MA, Bachman GC. Energetic costs of begging behaviour. In: Wright J, Leonard ML, editors. The evolution of begging: competition, cooperation and communication. Dordrecht: Kluwer; 2002.

Clotfelter ED. What cues do Brown-headed Cowbirds use to locate Redwinged Blackbird host nests? Anim Behav. 1998;55:1181-9.

Colombelli-Négrel D, Hauber ME, Kleindorfer S. Prenatal learning in an Australian songbird: habituation and individual discrimination in superb fairywren embryos. Proc Biol Sci. 2014;281:20141154.

Colombelli-Négrel D, Hauber ME, Robertson J, Sulloway FJ, Hoi H, Griggio M, et al. Embryonic learning of vocal passwords in superb fairy-wrens reveals intruder cuckoo nestlings. Curr Biol. 2012;22:2155-60.

Colombelli-Négrel D, Webster MS, Dowling JL, Hauber ME, Kleindorfer S. Vocal imitation of mother's calls by begging Red-backed Fairywren nestlings increases parental provisioning. Auk. 2016;133:273-85.

Courtney $\mathrm{J}$. The juvenile food-begging call of some fledgling cuckoos-vocal mimicry or vocal duplication by natural selection. Emu. 1967;67:154-7.

Cunningham S, Magrath RD. Functionally referential alarm calls in noisy miners communicate about predator behaviour. Anim Behav. 2017;129:171-9.

Dall SR, Giraldeau LA, Olsson O, McNamara JM, Stephens DW. Information and its use by animals in evolutionary ecology. Trends Ecol Evol. 2005;20:187-93.

Davies NB. Cuckoos, cowbirds, and other cheats. London: T. \& AD Poyser; 2000.

Davies NB. Cuckoo adaptations: trickery and tuning. J Zool. 2011;284:1-14.

Davies NB, Brooke MDL. An experimental study of co-evolution between the Cuckoo, Cuculus canorus, and its hosts. I. Host egg discrimination. J Anim Ecol. 1989;58:207-24.

Davies NB, Kilner RM, Noble DG. Nestling cuckoos, Cuculus canorus, exploit hosts with begging calls that mimic a brood. Proc R Soc B Biol Sci. 1998;273:693-9.
Davies NB, Madden JR, Butchart SH. Learning fine-tunes a specific response of nestlings to the parental alarm calls of their own species. Proc Biol Sci. 2004;271:2297-304.

Davies NB, Madden JR, Butchart SHM, Rutila J. A host-race of the cuckoo Cuculus canorus with nestlings attuned to the parental alarm calls of the host species. Proc R Soc B Biol Sci. 2006;273:693-9.

Davies NB, Welbergen JA. Cuckoo-hawk mimicry? An experimental test. Proc $R$ Soc B Biol Sci. 2008;275:1817-22.

Dawkins R, Krebs JR. Arms races between and within species. Proc R Soc B Biol Sci. 1979;205:489-511.

Dawson Pell FSE, Potvin DA, Ratnayake CP, Fernández-Juricic E, Magrath $\mathrm{RD}$, Radford AN. Birds orient their heads appropriately in response to functionally referential alarm calls of heterospecifics. Anim Behav. 2018;140:109-18.

De Mársico MC, Gantchoff MG, Reboreda JC. Host-parasite coevolution beyond the nestling stage? Mimicry of host fledglings by the specialist screaming cowbird. Proc Biol Sci. 2012;279:3401-8.

De Mársico MC, Ursino CA, Scardamaglia RC, Reboreda JC. Coevolutionary arms race between a specialist brood parasite, the Screaming Cowbird, and its host, the Grayish Baywing. J Ornithol. 2019;160:1221-33.

Dearborn DC. Brown-headed cowbird nestling vocalizations and risk of nest predation. Auk. 1999;116:448-57.

Deng Z, Lloyd H, Xia C, Moller AP, Liang W, Zhang Y. Components of variation in female common cuckoo calls. Behav Processes. 2019;158:106-12.

Dowling JL, Colombelli-Négrel D, Webster MS. Kin signatures learned in the egg? Red-backed fairy-wren songs are similar to their mother's in-nest calls and songs. Front Ecol Evol. 2016:4:48.

Duckworth JW. Responses of breeding reed warblers Acrocephalus scirpaceus to mounts of sparrowhawk Accipiter nisus, cuckoo Cuculus canorus and jay Garrulus glandarius. Ibis. 1991;133:68-74.

Dutour M, Cordonnier M, Léna J-P, Lengagne T. Seasonal variation in mobbing behaviour of passerine birds. J Ornithol. 2019;160:509-14.

Fallow PM, Pitcher BJ, Magrath RD. Alarming features: birds use specific acoustic properties to identify heterospecific alarm calls. Proc Biol Sci. 2013;280:20122539.

Feeney WE, Troscianko J, Langmore NE, Spottiswoode CN. Evidence for aggressive mimicry in an adult brood parasitic bird, and generalized defences in its host. Proc Biol Sci. 2015;282:893-6.

Feeney WE, Welbergen JA, Langmore NE. The frontline of avian brood parasite-host coevolution. Anim Behav. 2012;84:3-12.

Fishbein AR, Idsardi WJ, Ball GF, Dooling RJ. Sound sequences in birdsong: how much do birds really care? Philos Trans R Soc Lond B Biol Sci. 2020;375:20190044

Flower TP, Gribble M, Ridley AR. Deception by flexible alarm mimicry in an African bird. Science. 2014;344:513-6.

Garamszegi LZ, Avilés JM. Brood parasitism by brown-headed cowbirds and the expression of sexual characters in their hosts. Oecologia. 2005;143:167-77.

Gill SA, Neudorf DL, Sealy SG. Host responses to cowbirds near the nest: cues for recognition. Anim Behav. 1997;53:1287-93.

Gloag R, Kacelnik A. Host manipulation via begging call structure in the broodparasitic shiny cowbird. Anim Behav. 2013;86:101-9.

Gluckman T-L, Mundy NI. Cuckoos in raptors' clothing: barred plumage illuminates a fundamental principle of Batesian mimicry. Anim Behav. 2013;86:1165-81.

Godard R. Long-term memory of individual neighbours in a migratory songbird. Nature. 1991;350:228-9.

Grim T. The evolution of nestling discrimination by hosts of parasitic birds: why is rejection so rare? Evol Ecol Res. 2006;8:785-802.

Grim T. Are Blackcaps (Sylvia atricapilla) defending their nests also calling for help from their neighbours? J Ornithol. 2008;149:169-80.

Grim T, Kleven O, Mikulica O. Nestling discrimination without recognition: a possible defence mechanism for hosts towards cuckoo parasitism? Proc Biol Sci. 2003;270(Suppl 1):S73-5.

Haff TM, Magrath RD. Calling at a cost: elevated nestling calling attracts predators to active nests. Biol Lett. 2011;7:493-5.

Haff TM, Magrath RD. Learning to listen? Nestling response to heterospecific alarm calls. Anim Behav. 2012;84:1401-10.

Haskell D. Experimental evidence that nestling begging behaviour incurs a cost due to nest predation. Proc R Soc Lond B Biol Sci. 1994;257:161-4. 
Haskell D. Begging behaviour and nest predation. In: Wright J, Leonard ML, editors. The evolution of begging: competition, cooperation and communication. Dordrecht: Kluwer; 2002.

Haskell DG. The effect of predation on begging-call evolution in nestling wood warblers. Anim Behav. 1999;57:893-901.

Hauber ME, Dearborn DC. Parentage without parental care: what to look for in genetic studies of obligate brood-parasitic mating systems. Auk. 2003;120:1-13.

Hauber ME, Kilner RM. Coevolution, communication, and host chick mimicry in parasitic finches: who mimics whom? Behav Ecol Sociobiol. 2007;61:497-503.

Hauber ME, Pearson HE, Reh A, Merges A. Discrimination between host songs by brood parasitic brown-headed cowbirds (Molothrus ater). Anim Cogn. 2002;5:129-37.

Hauber ME, Ramsey CK. Honesty in host-parasite communication signals: the case for begging by fledgling brown-headed cowbirds Molothrus ater. J Avian Biol. 2003;34:339-44.

Honza M, Taborsky B, Taborsky M, TeuschI Y, Vogl W, Moksnes A, et al. Behaviour of female common cuckoos, Cuculus canorus, in the vicinity of host nests before and during egg laying: a radiotelemetry study. Anim Behav. 2002;64:861-8.

Hurd CR. Interspecific attraction to the mobbing calls of blackcapped chickadees (Parus atricapillus). Behav Ecol Sociobiol. 1996;38:287-92.

Hurd PL, Enquist M. A strategic taxonomy of biological communication. Anim Behav. 2005:70:1155-70

Jamie GA, de Silva WG. Similarity of the calls of juvenile pied cuckoo Clamator jacobinus and its Sri Lankan host species, yellow-billed babbler Turdoides affinis. Forktail. 2014;30:133-4.

Jamie GA, Kilner RM. Begging call mimicry by brood parasite nestlings: adaptation, manipulation and development. In: Soler M, editor. Avian brood parasitism Fascinating life sciences. Cham: Springer; 2017. p. 517-38.

Jelínek V, Karasová T, Weidinger K, Procházka P, Honza M. Do common cuckoo chicks suffer nest predation more than host nestlings? Behav Ecol Sociobiol. 2016;70:1975-87.

Jelínek V, Šulc M, Weidinger K, Honza M. Parent-absent begging and the risk of nest predation. J Ornithol. 2019;160:127-36.

Kacelnik A, Cotton PA, Stirling L, Wright J. Food allocation among nestling starlings: sibling competition and the scope of parental choice. Proc $R$ Soc Lond B Biol Sci. 1995;259:259-63.

Kalb N, Anger F, Randler C. Subtle variations in mobbing calls are predatorspecific in great tits (Parus major). Sci Rep-UK. 2019;9:6572.

Kalb N, Randler C. Behavioral responses to conspecific mobbing calls are predator-specific in great tits (Parus major). Ecol Evol. 2019;9:9207-13.

Katsis AC, Davies MH, Buchanan KL, Kleindorfer S, Hauber ME, Mariette MM. Prenatal exposure to incubation calls affects song learning in the zebra finch. Sci Rep-UK. 2018:8:15232.

Khayutin SN. Sensory factors in the behavioral ontogeny of altricial birds. Adv Stud Behav. 1985;15:105-52

Kilner RM, Noble DG, Davies NB. Signals of need in parent-offspring communication and their exploitation by the common cuckoo. Nature. 1999;397:667-72.

Kim H, Lee J-W, Yoo J-C. Comparing vocal structures of the parasitic and nonparasitic groups in Cuculinae. Avian Res. 2017:8:27.

Kisilevsky BS, Hains SM, Brown CA, Lee CT, Cowperthwaite B, Stutzman SS, et al. Fetal sensitivity to properties of maternal speech and language. Infant Behav Dev. 2009;32:59-71.

Kleindorfer S, Evans C, Colombelli-Négrel D. Females that experience threat are better teachers. Biol Lett. 2014;10:20140046.

Kleindorfer S, Evans C, Hauber ME, Colombelli-Négrel D. Could prenatal sound discrimination predict vocal complexity later in life? BMC Zoology. 2018;3:11-9.

Kondo N, Watanabe S. Contact calls: Information and social function. Jpn Psychol Res. 2009;51:197-208.

Langmore NE, Cockburn A, Russell AF, Kilner RM. Flexible cuckoo chick-rejection rules in the superb fairy-wren. Behav Ecol. 2009;20:978-84.

Langmore NE, Maurer G, Adcock GJ, Kilner RM. Socially acquired host-specific mimicry and the evolution of host races in Horsfield's bronze-cuckoo Chalcites basalis. Evolution. 2008;62:1689-99.

Langmore NE, Spottiswoode CN. Visual trickery in avian brood parasites. In: Hughes DP, Brodeur J, Thomas F, editors. Host manipulation by parasites. Oxford: Oxford University Press; 2012
Langmore NT, Hunt S, Kilner RM. Escalation of a coevolutionary arms race through host rejection of brood parasitic young. Nature. 2003:422:157-60.

Langmore NE, Stevens M, Maurer G, Heinsohn R, Hall ML, Peters A, et al. Visual mimicry of host nestlings by cuckoos. Proc Biol Sci. 2011;278:2455-63.

Lee J-W, Kim H-N, Yoo S, Yoo J-C. Common cuckoo females may escape male sexual harassment by color polymorphism. Sci Rep-UK. 2019:9:7515.

Leech SM, Leonard ML. Begging and the risk of predation in nestling birds. Behav Ecol. 1997:8:644-6.

Leonard M, Horn A. Dynamics of calling by tree swallow (Tachycineta bicolor) nestmates. Behav Ecol Sociobiol. 2001:50:430-5.

Leonard ML, Horn AG. Ambient noise and the design of begging signals. Proc Biol Sci. 2005:272:651-6.

Leonard ML, Horn AG, Porter J. Does begging affect growth in nestling tree swallows, Tachycineta bicolor? Behav Ecol Sociobiol. 2003;54:573-7.

Li D, Wei H, Zhang Z, Liang W, Stokke BG. Oriental reed warbler (Acrocephalus orientalis) nest defence behaviour towards brood parasites and nest predators. Behaviour. 2015;152:1601-21.

Liang W, Møller AP. Hawk mimicry in cuckoos and anti-parasitic aggressive behavior of barn swallows in Denmark and China. J Avian Biol. 2015;46:216-23.

Lichtenstein G. Selfish begging by screaming cowbirds, a mimetic brood parasite of the bay-winged cowbird. Anim Behav. 2001;61:1151-8.

Lorenzana JC, Sealy SG. Are begging calls of generalist parasitic cowbirds adapted for brood parasitism? UFS (Delta Marsh). Annu Rep. 1996;31:85-93.

Louder MIM, Balakrishnan CN, Louder AAN, Driver RJ, London SE, Hauber ME. An acoustic password enhances auditory learning in juvenile brood parasitic cowbirds. Curr Biol. 2019;29(4045-51):e3.

Lyon BE, Gilbert GS. Rarely parasitized and unparasitized species mob and alarm call to cuckoos: implications for sparrowhawk mimicry by brood parasitic cuckoos. Wilson J Ornithol. 2013;125:627-30.

Ma L, Yang C, Liang W. Hawk mimicry does not reduce attacks of cuckoos by highly aggressive hosts. Avian Res. 2018;9:35.

Madden JR, Davies NB. A host-race difference in begging calls of nestling cuckoos Cuculus canorus develops through experience and increases host provisioning. Proc Biol Sci. 2006;273:2343-51.

Madden JR, Kilner RM, Davies NB. Nestling responses to adult food and alarm calls: 1 . Species-specific responses in two cowbird hosts. Anim Behav. 2005a;70:619-27.

Madden JR, Kilner RM, Davies NB. Nestling responses to adult food and alarm calls: 2. Cowbirds and red-winged blackbirds reared by eastern phoebe hosts. Anim Behav. 2005b;70:629-37.

Marler P. Bird calls: a cornucopia for communication. In: Marler P, Slabbekoorn H, editors. Nature's music. San Diego: Academic Press; 2004.

Marton A, Fülöp A, Ozogány K, Moskát C, Bán M. Host alarm calls attract the unwanted attention of the brood parasitic common cuckoo. Sci RepUK. 2019;9:1-11.

McLean LG, Griffin JM. Structure, function, and mimicry in begging calls of passerines and cuckoos. Acta Int Ornithol Congress. 1991;2:1273-84.

Mclean IG, Waas JR. Do cuckoo chicks mimic the begging calls of their hosts? Anim Behav. 1987;35:1896-8.

Møller AP, Stokke BG, Samia DSM. Hawk models, hawk mimics, and antipredator behavior of prey. Behav Ecol. 2015;26:1039-44.

Montgomerie RD, Weatherhead PJ. Risk and rewards of nest defence by parent birds. Q Rev Biol. 1988;63:167-87.

Moon C, Lagercrantz H, Kuhl PK. Language experienced in utero affects vowel perception after birth: a two-country study. Acta Paediatr. 2013;102:156-60.

Morton ES, Farabaugh SM. Infanticide and other adaptations of the nestling striped cuckoo Tapera naevia. Ibis. 1979;121:212-3.

Moskát C. Nest defence and egg rejection in great reed warblers over the breeding cycle: are they synchronised with the risk of brood parasitism? Ann Zool Fenn. 2005:42:579-86.

Moskát C, Elek Z, Bán M, Geltsch N, Hauber ME. Can common cuckoos discriminate between neighbours and strangers by their calls? Anim Behav. 2017;126:253-60.

Mundy PJ. Vocal mimicry of their hosts by nestlings of the great spotted cuckoo and striped crested cuckoo. Ibis. 1973;115:602-4. 
Neuenschwander S, Brinkhof MW, Kölliker M, Richner H. Brood size, sibling competition, and the cost of begging in great tits (Parus major). Behav Ecol. 2003;14:457-62.

Nieder A, Mooney R. The neurobiology of innate, volitional and learned vocalizations in mammals and birds. Philos Trans R Soc Lond B Biol Sci. 2020;375:20190054.

Noguera JC, Velando A. Bird embryos perceive vibratory cues of predation risk from clutch mates. Nat Ecol Evol. 2019;3:1225-32.

Noh H-J, Gloag R, Langmore NE. True recognition of nestlings by hosts selects for mimetic cuckoo chicks. Proc R Soc B: Biol Sci. 2018;285:20180726.

Norman RF, Robertson RJ. Nest-searching behavior in the brown-headed cowbird. Auk. 1975;92:610-1.

Pagnucco K, Zanette L, Clinchy M, Leonard ML. Sheep in wolf's clothing: host nestling vocalizations resemble their cowbird competitor's. Proc R Soc B Biol Sci. 2008;275:1061-5.

Partan SR. Ten unanswered questions in multimodal communication. Behav Ecol Sociobiol. 2013;67:1523-39.

Patterson TL, James LPK. Reproductive value and appropriateness of response to predators by white-crowned sparrows. Behav Ecol Sociobiol. 1980;7:227-31.

Payne RB, Payne LL. Begging for parental care from another species: specialization and generalization in brood-parasitic finches. Dordrecht: Springer; 2002.

Platzen D, Magrath RD. Adaptive differences in response to two types of parental alarm call in altricial nestlings. Proc Biol Sci. 2005;272:1101-6

Price $\mathrm{K}$, Harvey $\mathrm{H}$, Ydenberg RON. Begging tactics of nestling yellow-headed blackbirds, Xanthocephalus xanthocephalus, in relation to need. Anim Behav. 1996;51:421-35.

Rackham H. Pliny: natural history. Cambridge: Harvard University Press; 1997.

Ranger GA. On three species of honey-guide; the Greater; (Indicator indicator) the Lesser (Indicator minor) and the Scaly-throated (Indicator variegatus). Ostrich. 1955:26:70-87.

Redondo T. Exploitation of host mechanisms for parental care by avian brood parasites. Etologia. 1993;3:235-97.

Redondo T, Reyna LAD. Vocal mimicry of hosts by great spotted cuckoo Clamator glandarius: further evidence. Ibis. 1988;130:540-4.

Rek P. Acoustic location of conspecifics in a nocturnal bird: the corncrake Crex crex. Acta Ethol. 2014:17:31-5.

Rivera M, Louder MIM, Kleindorfer S, Wan-chun L, Hauber ME. Avian prenatal auditory stimulation: progress and perspectives. Behav Ecol Sociobiol. 2018;72:112.

Rivers JW. Nest mate size, but not short-term need, influences begging behavior of a generalist brood parasite. Behav Ecol. 2007;18:222-30.

Rivers JW, Blundell MA, Loughin TM, Peer BD, Rothstein SI. The exaggerated begging behaviour of an obligate avian brood parasite is shared with a nonparasitic close relative. Anim Behav. 2013;86:529-36.

Rivers JW, Briskie JV, Rothstein SI. Have brood parasitic cowbird nestlings caused the evolution of more intense begging by host nestlings? Anim Behav. 2010:80:e1-5.

Rivers JW, Loughin TM, Rothstein SI. Brown-headed cowbird nestlings influence nestmate begging, but not parental feeding, in hosts of three distinct sizes. Anim Behav. 2010;79:107-16.

Rodríguez-Gironés MA, Zúñiga JM, Redondo T. Feeding experience and relative size modify the begging strategies of nestlings. Behav Ecol. 2002;13:782-5.

Rojas Ripari JM, Segura LN, Reboreda JC, De Mársico MC. Non-mimetic shiny cowbird nestlings escape discrimination by baywings in absence of host nest mates. Behav Ecol Sociobiol. 2019:73:135-43.

Rojas Ripari JM, Ursino CA, Reboreda JC, De Mársico MC. Innate development of acoustic signals for host parent-offspring recognition in the brood-parasitic Screaming Cowbird Molothrus rufoaxillaris. Ibis. 2018:161:717-29.

Rosenthal GG. The use of playbacks in behavioral experiments. US: Elsevier; 2019. p. 529-34

Rothstein SI. A model system for coevolution: avian brood parasitism. Annu Rev Ecol Syst. 1990;21:481-508.

Rubi TL, Stephens DW. Should receivers follow multiple signal components? An economic perspective. Behav Ecol. 2016:27:36-44
Samaš P, Žabková K, Petrusková T, Procházka P, Požgayová M, Honza M. Nestlings of the common cuckoo do not mimic begging calls of two closely related Acrocephalus hosts. Anim Behav. 2020;161:89-94.

Slabbekoorn H, Smith TB. Bird song, ecology and speciation. Philos Trans R Soc Lond B Biol Sci. 2002:357:493-503.

Smith JM. Parental investment: a prospective analysis. Anim Behav. 1977:25:1-9.

Smith HG, Montgomerie R. Nestling American robins compete with siblings by begging. Behav Ecol Sociobiol. 1991;29:307-12.

Soler M. Breeding strategy and begging intensity: influences on food delivery by parents and host selection by parasitic cuckoos. In: Wright J, Leonard $\mathrm{ML}$, editors. The evolution of begging: competition, cooperation and communication. Dordrecht: Kluwer Academic; 2002.

Soler M. Long-term coevolution between avian brood parasites and their hosts. Biol Rev. 2014;89:688-704.

Soler M. Begging behaviour, food delivery and food acquisition in nests with brood parasitic nestlings. In: Soler M, editor. Avian brood parasitism. Fascinating life sciences. Cham: Springer; 2017. p. 493-515.

Soler M, de Neve L, Macías-Sánchez E, Pérez-Contreras T. Great spotted cuckoos respond earlier to the arrival of feeding foster parents and perform less erroneous begging when hungry than their magpie host nest-mates. J Avian Biol. 2019:50:e01952

Soler M, Soler JJ, Martinez JG, Møller AP. Magpie host manipulation by great spotted cuckoos: evidence for an Avian Mafia? Evolution. 1995:49:770-5.

Suzuki TN. Parental alarm calls warn nestlings about different predatory threats. Curr Biol. 2011:21:R15-6.

Suzuki TN. Referential mobbing calls elicit different predator-searching behaviours in Japanese great tits. Anim Behav. 2012;84:53-7.

Suzuki TN. Communication about predator type by a bird using discrete, graded and combinatorial variation in alarm calls. Anim Behav. 2014:87:59-65.

Thorogood R, Davies NB. Hawk mimicry and the evolution of polymorphic cuckoos. Chin Birds. 2013;4:39-50

Trnka A, Grim T. Color plumage polymorphism and predator mimicry in brood parasites. Front Zool. 2013:10:25-34.

Trnka A, Prokop P. The effectiveness of hawk mimicry in protecting cuckoos from aggressive hosts. Anim Behav. 2012:83:263-8.

Trnka A, Prokop P, Grim T. Uncovering dangerous cheats: how do avian hosts recognize adult brood parasites? PLoS ONE. 2012;7:e37445.

Trnka A, Trnka M, Grim T. Do rufous common cuckoo females indeed mimic a predator? An experimental test. Biol J Linn Soc. 2015;1 16:134-43.

Uyehara JC, Narins PM. Nest defense by willow flycatchers to brood-parasitic intruders. Condor. 1995:97:361-8.

Villain A. Acoustic communication in female songbirds: functions, flexibility and plasticity in calls. PhD Thesis. Lyon: University of Lyon. 2016.

Voipio P. The hepaticus variety and the juvenile types of the cuckoo. Ornis Fenn. 1953;30:97-117.

Walton B, Kershenbaum A. Heterospecific recognition of referential alarm calls in two species of lemur. Bioacoustics. 2019;28:592-603.

Wang J, Ma L, Liang W, Yang C. Responses of cuckoo hosts to alarm signals of different nest intruders in non-nesting areas. Zool Res. 2020;41:345-50.

Wang J, Yang C. Specific responses of cuckoo hosts to different alarm signals according to breeding stage: a test of the offspring value hypothesis. Curr Zool. 2020. https://doi.org/10.1093/cz/zoaa021.

Welbergen JA, Davies NB. Reed warblers discriminate cuckoos from sparrowhawks with graded alarm signals that attract mates and neighbours. Anim Behav. 2008:76:811-22.

Welbergen JA, Davies NB. Strategic variation in mobbing as a front line of defense against brood parasitism. Curr Biol. 2009;19:235-40.

Welbergen JA, Davies NB. A parasite in wolf's clothing: hawk mimicry reduces mobbing of cuckoos by hosts. Behav Ecol. 2011;22:574-9.

Whittingham MJ, Butler SJ, Quinn JL, Cresswell W. The effect of limited visibility on vigilance behaviour and speed of predator detection: implications for the conservation of granivorous passerines. Oikos. 2004;106:377-85.

Wojas LE, Podkowa PW, Osiejuk TS. A nocturnal rail with a simple territorial call eavesdrops on interactions between rivals. PLoS ONE. 2018;13:e0197368.

Yang C, Huang J, Liang W, Møller AP. Absence of anti-parasitic defenses in an Asian population of the magpie, a regular host of the great spotted cuckoo in Europe. Curr Zool. 2020. https://doi.org/10.1093/cz/zoaa018. 
Yang C, Liang W, Moller AP. Similar immediate costs of raising cuckoo and host chicks can hardly explain low levels of antiparasite defence in hosts. A comment on: Samas et al. (2018). Proc Biol Sci. 2019;286:20182430.

Yang C, Si X, Liang W, Møller AP. Spatial variation in egg polymorphism among cuckoo hosts across four continents. Curr Zool. 2020. https://doi. org/10.1093/cz/zoaa011.

Yang C, Wang L, Cheng SJ, Hsu YC, Liang W, Moller AP. Nest defenses and egg recognition of yellow-bellied prinia against cuckoo parasitism. Naturwissenschaften. 2014:101:727-34.

Yasukawa K, Sollenberger J, Lindsey-Robbins J, DeBruyn E. Calling in the face of danger: do nestling Red-winged Blackbirds (Agelaius phoeniceus) suppress begging in response to predator playbacks? Auk. 2020;137:ukz071.

Yoo S, Kim HN, Lee JW, Yoo JC. Seasonal and diurnal patterns of population vocal activity in avian brood parasites. Ibis. 2020;162:1001-11.

York JE, Davies NB. Female cuckoo calls misdirect host defences towards the wrong enemy. Nat Ecol Evol. 2017;1:1520-5.
Yu J, Lu H, Sun W, Liang W, Wang H, Møller AP. Heterospecific alarm-call recognition in two warbler hosts of common cuckoos. Anim Cogn. 2019;22:1149-57.

Yu J, Lv W, Xu H, Bibi N, Yu Y, Jiang Y, et al. Function of note strings in Japanese Tit alarm calls to the Common Cuckoo: a playback experiment. Avian Res. 2017;8:22.

Yu J, Sun W, Liang W, Wang H, Møller AP. Differently sized cuckoos pose different threats to hosts. Curr Zool. 2019;22:1149-57.

Yu J, Wang L, Xing X, Yang C, Ma J, Møller AP, et al. Barn swallows (Hirundo rustica) differentiate between common cuckoo and sparrowhawk in China: alarm calls convey information on threat. Behav Ecol Sociobiol. 2016;70:171-8.

Yu J, Xing X, Jiang Y, Liang W, Wang H, Møller AP, et al. Alarm call-based discrimination between common cuckoo and Eurasian sparrowhawk in a Chinese population of great tits. Ethology. 2017;123:542-50.
Ready to submit your research? Choose BMC and benefit from:

- fast, convenient online submission

- thorough peer review by experienced researchers in your field

- rapid publication on acceptance

- support for research data, including large and complex data types

- gold Open Access which fosters wider collaboration and increased citations

- maximum visibility for your research: over $100 \mathrm{M}$ website views per year

At BMC, research is always in progress.

Learn more biomedcentral.com/submissions 